\title{
OS MEIOS DE COMUNICAÇÃO E A PRÁTICA POLÍTICA
}

\author{
LUIS FELIPE MIGUEL
}

O prodigioso desenvolvimento dos meios de comunicação, ao longo do século XX, modificou todo o ambiente político. O contato entre líderes políticos e sua base, a relação dos cidadãos com o universo das questões públicas e mesmo o processo de governo sentiram, e muito, o impacto da evolução tecnológica da mídia. Já no começo do século, fez-se notar a presença do rádio, secundado pelo cinema, que se mostrou um importante instrumento de propaganda. Os novos meios exigiam novos tipos de políticos, que soubessem como utilizá-los. Cada um à sua maneira, Franklin Roosevelt, nos Estados Unidos, e Hitler, na Alemanha, tornaramse símbolos da política da era do rádio. (Assim como Hollywood e a UFA berlinense representaram duas formas diferentes de aproveitamento político do cinema.) Mas o meio dominante, desde que surgiu, e que por enquanto não parece ser desafiado pelas novas tecnologias, é a televisão. Ela revolucionou nossa percepção do mundo, em especial do mundo social e, dentro dele, da atividade política.

Ocupando uma posição cada vez mais destacada na vida de seus espectadores (sempre mais numerosos), como fonte de informação e de entretenimento, a televisão reorganizou os ritmos da vida cotidiana, os espaços domésticos e, também, as fronteiras entre diferentes esferas sociais. Como demonstrou Joshua Meyrowitz, a mídia eletrônica, sobretudo a TV, rompeu a segmentação de públicos própria da mídia impressa e contribuiu para redefinir as relações entre mulheres e homens, crianças e adultos, leigos e especialistas ${ }^{1}$. Aprofundou as transformações no discurso político, de certa maneira unindo o sentimento de intimidade, transmitido pelo rádio, com o apelo imagético próprio do cinema.

\footnotetext{
1 Meyrowitz, No Sense of Place. As referências bibliográficas completas estão ao final do texto.
} 
Evidentemente, os cientistas políticos não puderam ignorar mudanças tão significativas e manifestas. Mas, em grande medida herdeiros de modelos que nascem ainda no período pré-midiático, têm dificuldade em incorporar de forma expressiva os meios de comunicação às suas reflexões. Em seu livro pioneiro, publicado na década de 1920, Walter Lippmann lamentava o fato de que "a ciência política é ensinada nas faculdades como se os jornais não existissem"2. Oitenta anos depois, é possível dizer que a ciência política já reconhece a existência do jornal, bem como do rádio, da televisão e até da internet. Mas em geral não vê neles maior importância.

Um exemplo emblemático vem de um dos livros mais festejados da ciência política brasileira dos últimos anos, fruto de uma extensa pesquisa e da análise minuciosa dos resultados de uma série de surveys nacionais, especialmente desenhados para o projeto $^{3}$. Numa obra dedicada ao estudo da "cultura política", isto é, das crenças e atitudes relativas à política e suas instituições, a mídia brilha como a grande ausente. Referida de passagem, aqui e ali, nunca é incorporada como uma variável significativa para a compreensão das idéias políticas compartilhadas por uma população.

Longe de se tratar de um caso isolado, a postura é característica da grande maioria dos estudos políticos, tanto nacionais quanto estrangeiros. $\mathrm{O}$ recorte da "política", que a ciência política faz, inclui governos, partidos e parlamentos; dependendo das preocupações específicas e das inclinações de cada um, também participam movimentos sociais, militares, elites econômicas ou a igreja. Os meios de comunicação de massa ficam (quase) invariavelmente de fora. Ou então são vistos como meros transmissores dos discursos dos agentes e das informações sobre a realidade, neutros e portanto negligenciáveis ${ }^{4}$. (Cumpre observar que esta também é a visão da política que a própria mídia costuma transmitir, na qual raras vezes aparece como agente.)

Se os cientistas políticos tendem a restringir a importância da mídia, os estudiosos da comunicação costumam, como observou Rubim, exagerá-la, a ponto de julgar que a política, totalmente dominada pela lógica dos meios, tornou-se um mero espetáculo entre outros ${ }^{5}$. Neal Gabler, ao apresentar a tese da superação da realidade pelo entretenimento, apenas deu uma roupagem mais provocativa a algo que, em certos círculos, já ganha foros de lugar comum 6 . Uma das pontas-de-lança dessa nova per-

\footnotetext{
2 Lippmann, Public opinion, p. 203.

3 Moisés, Os brasileiros e a democracia.

4 Esta é a percepção que transparece na obra recente de Castells, $O$ poder da identidade, pp. 161-2.

5 Ver Rubim, Comunicação e política, p. 12.

6 Gabler, Vida, o filme.
} 
cepção, a revista George, fundada pelo falecido "John John" Kennedy, baseia sua linha editorial na idéia de que parlamentares e governantes devem ser encarados de maneira similar a atores, cantores, apresentadores de programas de auditório e outras estrelas do ramo do divertimento. Ou então, como escreveu um diretor de jornal brasileiro, a política se tornou "um ramo da publicidade"7. É uma afirmação que, para além de sua razoabilidade imediata - o avanço das técnicas publicitárias é uma das características mais visíveis das disputas eleitorais das últimas décadas - leva a ignorar a permanência, transformada, de uma lógica especificamente política dentro do quadro cada vez mais midiático que baliza sua ação.

Este artigo esboça um modelo para a compreensão da relação entre meios de comunicação e política que seja capaz de apreender a interconexão entre as duas esferas e a centralidade crescente da mídia no jogo político atual, mas também o fato de que a política não se tornou um ramo do entretenimento ou da publicidade, como muitos querem - é regida por objetivos e lógica diferentes. Deve ser entendido como a enunciação de um conjunto de hipóteses de trabalho, cujo objetivo é guiar novas pesquisas na área. A principal ferramenta conceitual, retirada da sociologia de Pierre Bourdieu, é a idéia de campo. Para definir de maneira sucinta e provisória, um campo é um sistema de relações sociais que estabelece como legítimos certos objetivos, que assim se impõem "naturalmente" aos agentes que dele participam. Esses agentes, por sua vez, interiorizam o próprio campo, incorporando suas regras, também de maneira "natural", em suas práticas (o que Bourdieu chama de habitus) ${ }^{8}$.

O próprio Bourdieu tratou brevemente do impacto da mídia eletrônica sobre o campo político (e também sobre o campo acadêmico). Mas fê-lo numa obra polêmica, destinada a alertar para o peso excessivo dos meios comunicação de massa na formação das reputações políticas e universitárias; isto é, uma obra de combate, que almejava contribuir para a restauração da autonomia desses campos ${ }^{9}$. Em muitos casos, Bourdieu não faz mais do que traduzir, para suas categorias, constatações há muito pre-

\footnotetext{
7 Frias Filho, "Vendem-se candidatos". Outra formulação, de um ex-jornalista e professor de jornalismo estadunidense: a televisão "direcionou a política para sua própria essência: entretenimento visual". Janeway, Republic of denial, p. 60. Mais matizada, uma posição similar aparece em Gomes, "Propaganda política, ética e democracia".

8 Trata-se de um conceito complexo, que não admite ser encapsulado em umas poucas sentenças; ao longo deste artigo, enfatizarei sobretudo os aspectos mais relevantes para a discussão em tela. Para introduções úteis ao conceito de campo, ver Pinto, Pierre Bourdieu et la théorie du monde social, pp. 79-108; Jenkins, Pierre Bourdieu, pp. 66-102; e, do próprio sociólogo, Bourdieu (com Wacquant), Réponses, pp. 71-90.

9 Bourdieu, Sur la télévision.
} 
sentes na literatura sobre comunicação e política. Fora alguns insights estimulantes, pouco há, no livro, que avance para uma compreensão mais sistemática da relação entre mídia e política como campos relativamente independentes, na medida em que retêm sua própria lógica, mas sobrepostos, já que interferem, em larga escala, um no outro.

\section{A CENTRALIDADE DA MÍDIA}

É necessário, em primeiro lugar, o reconhecimento de que a mídia é um fator central da vida política contemporânea e que não é possível mudar este fato. Ou seja, é ocioso alimentar a nostalgia de "tempos áureos" da política, quando imperava o verdadeiro debate de idéias, sem a preocupação com a imagem ou a contaminação pelas técnicas da publicidade comercial ${ }^{10}$. Em primeiro lugar, porque um retorno ao passado é implausível. Mas também porque tal época de ouro nunca existiu. Antes do advento da televisão, outros fatores "viciavam" o discurso político. Se hoje é importante que o candidato tenha um rosto atraente, antes pesavam mais a técnica retórica, o timbre de voz ou mesmo o talhe do corpo, já que indivíduos altos e corpulentos se destacavam mais em meio à multidão ou no palanque. Em suma, mesmo que se possa lamentar a atual banalização do discurso político, nunca houve nada parecido a um debate "puro" de idéias, desligadas daqueles que as enunciam.

Ao mesmo tempo, os meios de comunicação de massa ampliam o acesso aos agentes políticos e a seus discursos, que ficam expostos, de forma mais permanente, aos olhos do grande público. Parte da nostalgia da política pré-midiática se deve à ausência atual de "grandes líderes". Como observa Meyrowitz, isto se deve não à falta de candidatos a esta posição, mas "à superabundância de informações sobre eles" 11 , isto é, à exposição de suas falhas, vacilações e equívocos. Para quem sonha com o glamour de um mundo salpicado de grandes homens, isto é mau. Do ponto de vista da prática democrática, porém, a desmitificação dos líderes políticos pode ser encarada como um progresso.

10 Como no contraste, comum em determinada literatura, entre os debates entre Lincoln e Douglas, em meados do século 19, com suas discussões profundas de temas controversos, e os debates televisivos de hoje, quando a cor da gravata importa mais do que aquilo que está sendo dito. Ver, entre outros, Lasch, $A$ rebelião das elites e a traição da democracia, pp. 191-3.

11 Meyrowitz, No sense of place, p. 270. 
Da mesma forma, muitos criticam o efeito deletério da mídia sobre a coesão social e a crença nas instituições políticas ${ }^{12}$. A televisão, em primeiro lugar, insularia as pessoas em suas vidas privadas, minando a convivência em comunidade, base da confiança interpessoal e da participação política. Além disso, a mídia colocar-se-ia à parte dos esforços nacionais, o que se traduziria em seu desrespeito até mesmo pelos segredos de guerra; a ênfase do noticiário nos escândalos solaparia a credibilidade nos políticos; em suma, seria abalada a percepção de que o Estado é o promotor do bem comum. Uma narrativa mais sofisticada atribui aos meios de comunicação o papel de deflagrador da "espiral do cinismo": a imprensa lê cinicamente a disputa política e os políticos se adaptam ao comportamento esperado, numa cadeia de alimentação mútua ${ }^{13}$. Sem dúvida, é legítimo deplorar a cobertura predominante sobre a arena política, que se reduz às estratégias da disputa pelo poder e nega espaço ao debate sobre os projetos de sociedade. Mas também cabe indagar se, do ponto de vista de uma cidadania esclarecida, a desconfiança em relação aos apelos pelo "bem público" e uma visão mais crítica sobre os interesses que movem os líderes políticos não são avanços consideráveis.

Parte desta suspeição contra a mídia está ligada a uma perspectiva elitista da prática política, que é perceptível, por exemplo, na reflexão do cientista político italiano Giovanni Sartori. Ele teve, em primeiro lugar, o mérito de considerar a questão dos meios eletrônicos de comunicação e, assim, chamar a atenção para eles com o peso de seu renome. Quando publicou A teoria da democracia revisitada, em 1987, Sartori ainda comungava do credo liberal de que os mecanismos de mercado bastariam para garantir a autonomia da opinião pública ${ }^{14}$. Ou seja: embora reconhecesse a importância dos provedores de informação no processo político democrático, tratava-se (ao menos para os regimes ocidentais) de um não-problema, dado que as instituições vigentes o resolveriam de maneira satisfatória.

Mas, pouco depois, no influente artigo "Videopolitica", Sartori vai apontar a influência excessiva da televisão como o principal obstáculo das democracias ocidentais ${ }^{15}$. Seus argumentos são retomados, com mais vagar, no livro Homo videns. Sartori diagnostica dois problemas interliga-

12 É o caso, por exemplo, de Fallows, Detonando a notícia; Sartori, Homo videns; Janeway, Republic of denial; e Putnam, "Tuning in, tuning out", pp. 667-80.

13 Cappella e Jamieson, Spiral of cynicism, pp. 9-10.

14 Sartori, A teoria da democracia revisitada, vol. 1, pp. 137-45.

15 Sartori, "Videpolitica". 
dos: o controle excessivo dos governos pela opinião pública, reduzindo o nível de racionalidade e a possibilidade de planejamento a médio-longo prazo das decisões políticas e administrativas, e o controle desta mesma opinião pela mídia eletrônica. A responsabilidade seria da televisão enquanto tal, um meio que inibiria o raciocínio que, de acordo com o cientista político italiano, só a palavra escrita promove ${ }^{16}$. Não é dada nenhuma importância às formas de utilização dos meios de comunicação eletrônicos ou aos interesses que os dirigem.

Se não há como reformar a TV, que é intrinsecamente nociva, nem, imagina-se, reduzir sua influência sobre o povo, a única solução seria diminuir (ainda mais) a influência popular sobre as decisões políticas, isolando a esfera decisória das influências vindas de baixo. Assim, Sartori se orienta na direção da redução da participação política, o que é coerente com a concepção de democracia que desenvolve em outros livros - uma concepção sensível à crítica platônica referente à incompetência das massas e que, rechaçando os ideais de autonomia cidadã, de igualdade e de alternância entre governantes e governados, enfatiza o papel seletivo do método eleitoral, reduzindo, enfim, a democracia à escolha dos "melhor preparados" para o exercício do poder.

Fica claro que parte dos problemas que a mídia coloca é, na verdade, própria da democracia de massas: a junção entre um demos heterogêneo, dividido por interesses contraditórios e portanto sempre em estado de conflito potencial, e a necessidade, comum a todas as sociedades, de manter um mínimo de unidade entre seus integrantes ${ }^{17}$. Se, na Grécia antiga, mulheres, escravos e metecos tivessem acesso à cidadania, suas instituições precisariam estar melhor posicionadas para lidar com a dissensão. Da mesma forma, a idealização promovida por Habermas, em sua reconstituição dos inícios da opinião pública, é possível porque a esfera pública burguesa do século XVIII era franqueada a uma parcela relativamente restrita e homogênea da população ${ }^{18}$. Ao contrário do que Habermas deixa transparecer, a exclusão de trabalhadores braçais e mulheres não era algo contingente, mas um traço crucial da realidade que descreve ${ }^{19}$.

16 Sartori, Homo videns, pp. 35-6.

17 Em seu famoso relatório à Comissão Trilateral, Huntington deixa claro que a incorporação política de grupos antes marginalizados, como os negros, era uma das causas da "instabilidade" da democracia estadunidense dos anos 70. Huntington, "The United States", esp. p. 114.

18 Habermas, Mudança estrutural da esfera pública. Para uma crítica às "ilusões liberais" do empreendimento habermasiano, ver Löwy, "A escola de Frankfurt e a modernidade".

19 Ver Fraser, "Rethinking the public sphere", pp. 117-8. 
Ou seja, num ambiente de acerbo conflito de interesses, é inimaginável que os meios de comunicação sejam os porta-vozes imparciais do debate político, como a imprensa européia teria sido em seus primórdios, ao menos na descrição edulcorada que Habermas faz dela ${ }^{20}$. Isto não significa que se deva descair para o conformismo, já que a mídia "sempre" defenderá certos segmentos sociais, mas sim que é necessário perceber que a mudança passa pela pressão da sociedade, isto é, dos grupos prejudicados pela forma dominante de gestão da comunicação. E, como se tenta mostrar na próxima seção, que o modelo normativo que deve orientar tal pressão não pode ser o que Habermas sustenta em sua idealização da esfera pública burguesa (e desenvolve mais tarde, em grau mais elevado de abstração, na teoria do agir comunicativo).

O elitismo que subjaz à ausência da mídia na análise da realidade política também pode ser apreciado por outro ângulo. Nas sociedades formalmente democráticas em que vivemos, é corrente a divisão da política em "bastidores", as salas secretas em que se fazem os acordos e se tomam as grandes decisões, e "palco", o jogo de cena representado para os não-iniciados, isto é, para o povo em geral ${ }^{21}$. O que ocorre no palco serviria apenas para distrair a platéia e manter a estabilidade do sistema, perpetuando o mito da democracia como "governo do povo". Por motivos óbvios, a mídia pertence a este segundo espaço - mas os fatos políticos relevantes ocorreriam no primeiro, nos "bastidores".

Não se trata de negar as imperfeições da democracia formal, que se caracteriza, de fato, pela limitação da participação política popular. Mas a distinção entre bastidores e palco merece ser relativizada. Em primeiro lugar, a passividade política da "massa" não se trata de um dado "da natureza", como quer a tradição do pensamento elitista. Ela precisa ser produzida. Aliás, uma investigação sobre o papel dos meios de comunicação na produção desta passividade seria de grande interesse. Como a produção da apatia é imperfeita, a massa irrompe, de tempos em tempos no jogo político, ou seja, a platéia invade o palco e tumultua aquilo que fora acertado nos bastidores.

Além disso, nos regimes formalmente democráticos, o povo mantém a prerrogativa de decidir quem exercerá o poder político. Ou, continuando com a metáfora, a platéia decide quem vai para os bastidores, e

\footnotetext{
${ }^{20}$ Para uma crítica à esfera pública habermasiana, centrada sobre a questão da imprensa, ver Garnham, "The media and the public sphere".

21 Ver, por exemplo, Balandier, Le pouvoir sur scènes.
} 
em qual posição (ou ao menos controla parte da decisão, já que os grandes patrões e os chefes militares, por exemplo, influenciam a política sem se submeterem ao crivo das eleições). Alguns autores reduzem o processo eleitoral a um ritual de coesão social, desprovido de conseqüências práti$\operatorname{cas}^{22}$, mas o argumento não se sustenta. As eleições alemãs de 1933, chilenas de 1970 e brasileiras de 1989 são exemplos, com diferentes graus de dramaticidade, de episódios em que a votação popular esteve repleta de consequiências para história desses países e mesmo da humanidade. E não é só no momento eleitoral que a voz da platéia se faz ouvir. O público não é indiferente ao que ocorre nos bastidores, nem estes são impermeáveis à sua curiosidade. Muitas vezes, uma "revelação" dos bastidores é um momento crucial do jogo político - Watergate e o impeachment de Collor são dois exemplos óbvios.

O que os elitistas apontam como "natural" - a desigualdade política, a profunda divisão entre governantes e governados - é fruto de uma organização social que concentra em poucas mãos o capital político. Alguns poucos monopolizam a capacidade de intervir no campo político exatamente porque os outros internalizam a própria impotência e oferecem o reconhecimento de que aqueles poucos são os "líderes". Se o reconhecimento social é a chave da conquista do capital político, avulta a importância da mídia, principal difusora do prestígio e do reconhecimento social nas sociedades contemporâneas.

\section{MÍDIA E REPRESENTAÇÃO POLÍTICA}

O que se está querendo dizer é que sistemas políticos consensuais exigem um grau razoavelmente elevado de homogeneidade prévia e, portanto, têm dificuldade de lidar com conflitos fundamentais de interesse. Em particular, eles não conseguem processar as demandas por igualdade que são parte tão importante das lutas políticas contemporâneas ${ }^{23}$. $\mathrm{Na}$ medida em que a redução da heterogeneidade está fora de cogitação (pois a ampliação do acesso formal à esfera política foi a principal conquista democrática do século XX), o desafio é a construção de modos de gestão do conflito que levem em conta, de forma mais justa, os diversos interes-

\footnotetext{
22 Edelman, The symbolic uses of politics.

23 Embora a autora relute em afirmar tais conclusões, elas se impõem a partir dos resultados da pesquisa de Mansbridge sobre o funcionamento de democracias "unitárias" (consensuais) a nível local e em ambientes de trabalho (Mansbridge, Beyond adversary democracy, pp. 233-302).
} 
ses sociais, isto é, que ampliem a igualdade política dos integrantes do demos. Dito de outra forma, o desafio é alcançar uma representação mais equânime dos diferentes interesses sociais nas esferas de decisão.

A representação política coloca uma série de graves problemas para a organização democrática, como os que dizem respeito aos critérios de representatividade, à vinculação entre os representantes e seus constituintes, ao risco de autonomização dos representantes em relação ao conjunto da sociedade etc. Na medida em que a superação da necessidade de representação não está colocada no horizonte ${ }^{24}$, o pensamento democrático deve continuar lidando com estas questões e buscando soluções, mesmo que sempre sejam provisórias. O que desejo assinalar aqui é que os meios de comunicação são, em si mesmos, uma esfera da representação política.

A mídia é, nas sociedades contemporâneas, o principal instrumento de difusão das visões de mundo e dos projetos políticos; dito de outra forma, é o local em que estão expostas as diversas representações do mundo social, associadas aos diversos grupos e interesses presentes na sociedade. O problema é que os discursos que ela veicula não esgotam a pluralidade de perspectivas e interesses presente na sociedade. As vozes que se fazem ouvir na mídia são representantes das vozes da sociedade, mas esta representação possui um viés ${ }^{25}$. O resultado é que os meios de comunicação reproduzem mal a diversidade social, o que acarreta conseqüências significativas para o exercício da democracia.

Se, como diz Nadia Urbinati, "na democracia representativa a exclusão política toma a forma de silênciô̂ ${ }^{26}$, esse silêncio não é apenas a ausência de um representante no parlamento. É a ausência de voz na disputa pelas representações do mundo social, que se trava nos meios de comunicação. No entanto, as concepções correntes da democracia tendem a ignorar ou desprezar esse fato.

As teorias hegemônicas da democracia trabalham com a idéia de que os interesses já estão dados, o problema constituindo na maneira de agregá-los. É uma perspectiva que reduz a importância da comunicação política. O equívoco é não perceber que, longe de serem dados a priori, os

\footnotetext{
24 Ao contrário do que fazem crer certas visões utópicas da utilização das novas tecnologias da informação. Sobre a questão, ver Miguel, "Democracia e novas tecnologias da informação".

25 O que já foi demonstrado empiricamente, de forma cabal. Ver, entre muitos outros: Entman, Democracy without citizens; Hallin, The "uncensored" war; McChesney, Rich media, poor democracy; Fallows, Detonando a notícia; Noelle-Neuman, La espiral del silencio; Page, Who deliberates?. Para o caso brasileiro: Berger, Campos em confronto; Kucinski, A síndrome da antena parabólica; Miguel, "Mídia e eleições".

26 Urbinati, "Representation as advocacy", p. 773.
} 
interesses e as preferências dos indivíduos são permanentemente definidos e redefinidos através da própria luta política, que vai enfatizar certas clivagens sociais em detrimento de outras, construir solidariedades e identidades coletivas, universalizar projetos e visões de futuro. A democratização da esfera política implica, portanto, tornar mais equânime o acesso aos meios de difusão das representações do mundo social.

Isto significa, em primeiro lugar, dar espaço na mídia às diferentes vozes presentes na sociedade, para que participem do debate político. Mas significa também, e crucialmente, gerar espaços que permitam aos grupos sociais, em especial os dominados, formular suas próprias interpretações sobre suas necessidades e seus interesses - aquilo que Nancy Fraser chama de "contra-públicos subalternos"27. O caminho, portanto, não passa pela "neutralidade" dos meios de comunicação, como se depreende do modelo habermasiano da esfera pública, mas por um verdadeiro pluralismo, que os mecanismos de mercado, por diversas razões, não provêem.

Entre estas razões estão a tendência à monopolização, que a concorrência econômica gera, e a tendência à uniformização dos produtos, ditada pela natural imitação das fórmulas exitosas. Mas a principal delas é, sem dúvida, o fato de que todos os grandes órgãos de mídia compartilham de uma mesma visão de mundo, que inclui em especial o compromisso com a ordem capitalista. O mercado da mídia está cada vez mais concentrado (e internacionalizado). As empresas que o dominam têm um peso crescente na economia como um todo. O fenômeno chamado de "convergência tecnológica" vêm agrupando indústrias de informação e entretenimento, de aparelhos eletrônicos e de telefonia em mega-conglomerados, que via de regra têm também participação em outros ramos de produção. Por fim, as empresas de mídia são em grande parte dependentes de outras grandes firmas capitalistas, suas anunciantes ${ }^{28}$.

Tal quadro deixa claro que os meios de comunicação, na forma em que existem hoje, dificilmente darão espaço para a expressão ou a constituição de interesses que ameacem as estruturas básicas do capitalismo. No entanto, é preciso frisar que o problema da mídia não é um mero "caso" da incompatibilidade constatada entre o aprofundamento da democracia e a manutenção das relações capitalistas de produção. De fato, o desequilíbrio de recursos que o capitalismo produz na esfera econômica transborda sem cessar para a esfera política, comprometendo a igualdade que é re-

27 Fraser, "Rethinking the public sphere", p. 123.

28 Ver McChesney, op. cit.; Bagdikian, The media monopoly; Dizard Jr., A nova mídia 
quisito para o exercício da democracia - um fenômeno que é apontado mesmo por autores vinculados à tradição liberal, como Robert Dahl ${ }^{29}$-, e a propriedade da mídia pode ser encarada como uma manifestação deste fato mais geral. No entanto, mesmo numa sociedade hipotética que tenha abolido as desigualdades materiais e em que os meios de produção estejam sob controle social ou autogestionário, o problema dos acesso aos meios de comunicação estará presente. Afinal, uma das características definidoras da mídia é a desigualdade entre emissor e receptores, ou seja, o fato de que os emissores formam um conjunto razoavelmente restrito em relação ao universo de receptores. Por isso, é importante entender a problemática da mídia como afim à problemática da representação política, isto é, como uma desigualdade que, embora influenciada por fatores econômicos (e outros), não se reduz a eles, sendo própria da organização política em sociedades populosas e complexas.

\section{CAMPO POLÍTICO, CAMPO DA MÍDIA}

Definidos os termos da relação entre mídia e política, torna-se necessário encontrar uma moldura conceitual que permita entendê-la. Sem tais ferramentas, boa parte da pesquisa na área se reduz à compilação de dados empíricos, que permitem observar a existência de tal ou qual viés nos meios de comunicação, ligá-los com determinado interesse econômico ou eleitoral, e não mais do que isto. Ou então adota uma perspectiva behaviorista e tenta medir o peso dos meios de comunicação sobre a opinião pública. Em geral, são usados surveys de opinião pública, procedimento que, mesmo quando correto do ponto de vista estatístico, apresenta problemas metodológicos graves, já que presume uma conexão entre o entrevistado e sua resposta que nem sempre se verifica ${ }^{30}$. Para suprir esta deficiências, desenvolveram-se técnicas de painel $^{31}$; no entanto, elas não conseguem envolver amostras representativas da população (para começar, a parcela que não aceita se submeter a várias sessões cansativas de questionários e discussões está por definição excluída) e, mais grave, o artificialismo da situação contamina seus resultados. O mesmo pode ser afir-

\footnotetext{
29 Dahl, Um prefácio à democracia econômica; Dahl, Democracy and its critics, pp. 324-32.

30 Ver Bourdieu, "L'opinion publique n'existe pas"; Bourdieu, Méditations pascaliennes, p. 74; Champagne, Faire l'opinion, pp. 96-118.

31 Por exemplo, Graber, Processing the news; Gamson, Talking politics.
} 
mado a fortiori dos experimentos de laboratório ${ }^{32}$. É possível dizer, de maneira geral, que o acúmulo de dados empíricos sobre a influência da mídia tem contribuído pouco para o aumento de nossa compreensão da relação entre meios de comunicação e sociedade, dada a ausência de um marco teórico mais adequado.

O conceito de campo permite entender a interação entre mídia e política, duas esferas que se guiam por lógicas diferentes, mas que interferem uma na outra. O campo político é, segundo a definição de Bourdieu, "o lugar em que se geram, na concorrência entre os agentes que nele se acham envolvidos, produtos políticos, problemas, programas, análises, comentários, conceitos, acontecimentos, entre os quais os cidadãos comuns, reduzidos ao estatuto de 'consumidores', devem escolher" 33 . Todo campo se define pela imposição de critérios próprios de avaliação da realidade, em especial pela fixação de objetivos que se apresentam como "naturais" para aqueles que deles participam — neste caso, a busca do poder político.

Assim, o campo seria "um universo obedecendo a suas próprias leis" 34 , expressão que sintetiza a autonomia, que todo campo almeja, e o fechamento sobre si próprio, que caracteriza a todos. No entanto, o fechamento encontra limites, muito claros no caso da política, que periodicamente precisa se abrir para os simples eleitores. O importante é observar que as posições no campo político não são mero reflexo das votações recebidas; basta lembrar de tantos campeões de voto, sejam eles radialistas, cantores ou esportistas, que ocupam um lugar menos do que secundário no Congresso. O capital político é uma forma de capital simbólico, isto é, dependente do reconhecimento fornecido pelos próprios pares. Como todos, em certos momentos-chave, lutam por votos, a popularidade contribui para tal reconhecimento, mas não é o único determinante.

Em Sobre a televisão, Bourdieu trata da influência que o campo jornalístico exerce tanto sobre a política quanto sobre o meio universitário. Não por acaso, pois ele julga que os campos político, jornalístico e das ciências sociais têm uma meta comum, que é "impor a visão legítima do mundo social" 35 . Ao que parece, o jornalismo estaria colonizando seus dois concorrentes - e o propósito de Bourdieu é denunciar uma interferência

\footnotetext{
32 Por exemplo, Cappella e Jamieson, Spiral of cynicism; Iyengar, Is anyone responsible?; Neuman, Just e Crigler, Common knowledge; Ceci e Kain, "Jumping on the bandwagon with the underdog"; Rosenberg e McCafferty, "The image and the vote".

33 Bourdieu, "A representação política", p. 164.

34 Bourdieu, Propos sur le champ politique, p. 52.

35 Apud Fristch, "Introduction", p. 22.
} 
que julga ilegítima. Cada vez mais, a visibilidade nos meios de comunicação se torna a condição essencial para a geração de capital político (ou acadêmico), o que significa a perda de autonomia destes campos. Contra a ameaça que a mídia eletrônica representa, aparece, na argumentação do autor, uma espécie de nostalgia da forma "pura" de produção de capital simbólico - quando, em boa parte de sua obra anterior, ele se dedicava exatamente a denunciar a espécie de violência simbólica que estava por trás das consagrações intelectuais e também políticas. Trata-se de um passo atrás em sua reflexão crítica, culminando na confissão do ideal, algo bizarro, de uma sociologia internada numa "torre de marfim", falando uma linguagem esotérica que afaste dela todo o público não especializado ${ }^{36}$.

Da forma como fica colocado, torna-se difícil entender a complexidade das relações entre mídia e política. Tudo se reduz à denúncia de uma intromissão inadequada; em outro momento, Bourdieu chega a incluir mídia dentro do campo político (na medida em que gera "efeitos" sobre este campo $)^{37}$. No entanto, como pretendo demonstrar ao longo do restante deste artigo, mídia e política formam dois campos diferentes, guardam certo grau de autonomia e a influência de um sobre o outro não é absoluta nem livre de resistências; na verdade, trata-se de um processo de mão dupla. Antes, porém, é necessário entender melhor a natureza do campo midiático e os influxos que se exercem sobre ele.

A autonomia do campo da mídia é permanentemente tensionada por sua inserção no campo econômico. É possível dizer que uma empresa de comunicação é um organismo bifronte. De um lado, obedece a seus imperativos profissionais específicos, que variam de acordo com o subcampo: a manutenção de determinados patamares de qualidade estética, no caso de programas de caráter ficcional ou cultural; fidelidade ao que é percebido como a realidade fática e busca da credibilidade, no jornalismo. De outro, a ampliação do faturamento e do lucro. Mesmo a luta pela audiência é ambígua. Vista como um fim em si mesma por parte dos integrantes do campo midiático, que têm a popularidade por objetivo (e são esses muitas vezes os que transitam para o campo político), ela é apenas um meio do ponto de vista da lógica econômica, que pode optar por sacrificar uma audiência maior em favor de outra que reúna certas qualidades, em especial o poder de compra, que a tornem mais interessante.

\footnotetext{
36 Bourdieu, Sur la télévision, p. 71. E também no sonho, com evidentes ecos comtianos, de uma sociologia que subordina as decisões políticas, graças a seu saber científico: ver Bourdieu, Propos sur le champ politique, pp. 43-4.

37 Id., p. 61.
} 
A percepção da influência do campo econômico sobre os meios de comunicação leva, muitas vezes, à denúncia de sua total ausência de autonomia. É o que motiva a lamentação permanente a respeito do baixo nível cultural e artístico das produções veiculadas nos meios de comunicação, da interferência abusiva dos anunciantes sobre o conteúdo dos programas (em especial o veto à divulgação de notícias que os prejudiquem) e da predominância, nos noticiários, do fait-divers - que, mimetizando a forma narrativa da ficção, cativa parcelas maiores da audiência, mas também degrada o nível de informação pública sobre as questões "sérias". No entanto, os jornalistas e produtores culturais possuem capacidade de resistência e se esforçam por respeitar, mesmo que em grau mínimo, os códigos profissionais que são próprios de seu campo. A ausência de qualquer autonomia em relação ao campo econômico, aliás, se mostra disfuncional para a mídia. Um exemplo eloqüente é a "revolução" que o executivo Mark Willes tentou promover, a partir de 1995, no jornal Los Angeles Times, impondo a cada setor da redação o imperativo de gerar lucro. Saudado com entusiasmo nas bolsas de valores, o projeto de Willes encontrou a resistência tanto de profissionais quanto de leitores e o executivo teve que se demitir no começo de 2000.

Em suma, é necessário reconhecer a persistência de certa autonomia do campo da mídia, o que faz com que os padrões de conduta compartilhados por seus integrantes sejam uma força atuante dentro dele. No caso específico do jornalismo, isto inclui um compromisso com a "verdade" e a "objetividade" que servem de critério para determinar a competência e a respeitabilidade pelos pares. A violação destas normas, notadamente em submissão a ditames econômicos ou políticos, é freqüente, mas impõe ônus que não podem ser ignorados.

\section{MÍDIA E CAPITAL POLÍTICO}

A influência mais evidente dos meios de comunicação sobre o campo político está na formação do capital político. Bourdieu distingue duas espécies básicas de capital político ${ }^{38}$. O capital "delegado" é aquele ligado à ocupação de um determinado cargo institucional, seja ele um mandato parlamentar ou executivo, uma função de confiança num escalão governamental ou uma posição de poder na estrutura partidária. $\mathrm{O}$ ex-ocu-

38 Bourdieu, “A representação política”, pp. 190-2. 
pante do cargo beneficia-se do prestígio obtido em seu exercício e pode continuar sua carreira política. Já o capital "transferido" nasce da conversão, para a política, de outro tipo de capital, obtido em campo diverso. É o caso daqueles que fazem da notoriedade artística ou profissional a alavanca para o sucesso nas urnas - Agnaldo Timóteo, Fernando Henrique Cardoso, Ronald Reagan, Cicciolina e Joe Ventura são exemplos propositalmente díspares. Mas o mesmo ocorre com economistas e engenheiros que são chamados para ocupar importantes funções decisórias no governo (conversão de capital técnico) ou empresários que ingressam na vida parlamentar após dispendiosas campanhas eleitorais (conversão de capital econômico).

O que se observa é que a visibilidade na mídia é, cada vez mais, componente essencial da produção do capital político. A presença em noticiários e talk-shows parece determinante do sucesso ou fracasso de um mandato parlamentar ou do exercício de um cargo executivo; isto é, na medida em que deve acrescentar algo ao capital político próprio do ocupante. Da mesma maneira, a celebridade midiática tornou-se o ponto de partida mais seguro para quem deseja se lançar na vida política - na forma, dependendo do perfil de cada um, de uma candidatura às eleições ou de um convite para uma função governamental.

Isto fica especialmente claro na grande quantidade de profissionais de mídia que ingressam na vida política, sobretudo ocupando cargos parlamentares. São radialistas, repórteres de televisão, apresentadores de programas de variedades ou "especialistas" (sobretudo advogados e psicólogos) com quadros naqueles programas. Os exemplos, só na política brasileira, são incontáveis: Antônio Britto, Celso Russomano, Cidinha Campos, Ratinho, João Paulo Bisol, Marta Suplicy, Hélio Costa ${ }^{39}$. No entanto, é possível aventar a hipótese de que o campo político impõe determinados limites à conversão do prestígio midiático. Se ele é útil para a conquista de um mandato parlamentar, alçar vôos mais altos exige uma espécie de "faxina" do capital simbólico, com o exercício de outras funções públicas e a desvinculação paulatina da fonte original de notoriedade. $\mathrm{O}$ caso de Ronald Reagan é ilustrativo. Quando se elegeu governador da Califórnia, ele já era mais o porta-voz dos interesses da "livre empresa" do que o medíocre ator de filmes B. Mesmo em campanhas posteriores, a dis-

39 Um caso exemplar é o do deputado Paulo ("Paulinho") Bornhausen. Herdeiro da tradicional oligarquia catarinense, filho e neto de ex-governadores do Estado, ele julgou útil, antes de ingressar na política eleitoral, comandar um programa popular numa rádio local. 
sociação do passado era buscada, ao ponto de seus anúncios de televisão exibirem deliberadamente uma qualidade técnica inferior, mostrando que não eram "coisa de Hollywood" 40 .

Embora uma pesquisa sistemática ainda esteja por ser feita, tudo indica que o sistema eleitoral condiciona, em parte, o volume da presença das estrelas midiáticas no parlamento. A representação proporcional favorece os portadores deste tipo de notoriedade, que encontra resistência em parte significativa do eleitorado e, portanto, encontra maiores obstáculos ao êxito em sistemas majoritários. Outro fator a ser considerado é a fragilidade ou robustez dos partidos. Partidos fortes contam, via de regra, com uma estrutura interna poderosa, com interesses consolidados e capacidade de se opor à ocupação de espaço pelos novatos oriundos da exposição à mídia.

Além disso, mesmo no caso brasileiro, não se pode ignorar a permanência de uma grande massa de políticos que desenvolvem suas carreiras às margens dos meios de comunicação de massa. São, por exemplo, parlamentares ancorados em redes clientelistas ou representantes de interesses corporativos. Eles podem ter uma atuação "apagada" (do ponto de vista do grande público), mas garantem eleições tranqüilas e a continuidade do mandato. Assim, é correto dizer que a mídia adquiriu um forte peso na formação do capital político e mesmo que, em alguma medida, condiciona as trajetórias políticas — já que a ausência de visibilidade nos meios de comunicação parece ser um empecilho sério para quem almeja os cargos eletivos mais importantes do poder executivo. Mas a mídia não possui o monopólio da produção ou distribuição deste capital; e o campo político (isto é, os agentes políticos de carreira mais tradicional) trata, por vezes com sucesso, de impor limites à influência da mídia, através da desvalorização simbólica dos tipos de notoriedade mais estreitamente associados aos meios de comunicação de massa.

\section{O CONTROLE SOBRE A AGENDA}

A influência dos meios de comunicação também é particularmente sensível num momento crucial do jogo político, a definição de agen$\mathrm{da}^{41}$. A pauta de questões relevantes, postas para a deliberação pública, é em grande parte condicionada pela visibilidade de cada questão nos meios

40 Diamond e Bates, The spot, p. 226.

41 Ao usar "definição de agenda" como tradução da expressão inglesa consagrada, agenda-setting, sigo Fuks, "Definição de agenda, debate público e problemas sociais". 
de comunicação. Dito de outra maneira, a mídia possui a capacidade de formular as preocupações públicas. O impacto da definição de agenda pelos meios é perceptível não apenas no cidadão comum, que tende a entender como mais importantes as questões destacadas pelos meios de comunicação, mas também no comportamento de líderes políticos e de funcionários públicos, que se vêem na obrigação de dar uma resposta àquelas questões.

Cumpre observar que a mídia não se limita à definição de agenda, no sentido de apresentação "neutra" de um elenco de assuntos, como por vezes transparece nos trabalhos pioneiros sobre o tema ${ }^{42}$. Assim, a idéia de definição de agenda será complementada pela noção de "enquadramento" (framing), adaptada da obra de Erving Goffman: a mídia fornece os esquemas narrativos que permitem interpretar os acontecimentos; na verdade, privilegia alguns destes esquemas, em detrimento de ou$\operatorname{tros}^{43}$. Há, porém, uma dificuldade para operacionalizar o conceito: como trabalhar com o que não está posto, isto é, com os enquadramentos alternativos? Como ver aquilo a que não se dá visibilidade? Como perceber o que a mídia não mostrou, se é a mídia que nos mostra o mundo?

$\mathrm{O}$ controle sobre a agenda e sobre a visibilidade dos diversos enquadramentos alicerça a centralidade dos meios de comunicação no processo político contemporâneo. Tal fato não passa despercebido dos agentes políticos, que hoje, em grande medida, orientam suas ações para o impacto presumível na mídia. São os "pseudo-eventos", como chamou Daniel Boorstin em seu estudo de 1961: acontecimentos que não são espontâneos, planejados com o objetivo de virarem notícia ${ }^{44}$. Tornaram-se tão corriqueiros que nem percebemos mais sua artificialidade; o exemplo mais comum é a entrevista (na medida em que é uma conversação que só ocorre com vistas a sua reprodução na mídia), mas o mesmo vale para grande parte das manifestações de massa, passeatas, encontros de líderes políticos e até convenções partidárias.

A preocupação principal de Boorstin é o jornalismo, que se teria desviado de sua função inicial, registrar os fatos, passando a produzilos. Mas não é difícil perceber seu impacto nos agentes políticos, que pre-

\footnotetext{
42 Cohen, The press and foreign policy, p. 13; McCombs e Shaw, "The agenda-setting function of mass media".

$43 \mathrm{O}$ conceito original de enquadramento, que não foi pensado especificamente para os meios de comunicação, está em Goffman, Frame analysis. Para adaptações à mídia, ver Gitlin, The whole world is watching, pp. 6-7; Gamson, Talking politics, p. 7; e Entman, "Framing".

44 Boorstin, The image, pp. 9-12.
} 
cisam pautar sua ação por critérios de "noticiabilidade"; isto é, que introjetam normas próprias do campo da mídia e se guiam por elas. Um exemplo é a trajetória do Students for a Democratic Society (SDS), grupo juvenil radical que se envolveu na luta contra a Guerra do Vietnã ${ }^{45}$. À medida em que ganhava acesso à mídia, o SDS trocava a direção colegiada por líderes individuais, já que, para a televisão, é mais fácil personalizar os movimentos coletivos em algumas poucas "estrelas", que se tornam seus porta-vozes; o trabalho educativo, de debates e palestras nos campi, foi relegado a segundo plano, em favor de mobilizações espetaculosas. $\mathrm{O}$ grupo arrebanhou numerosos novos adeptos, mas estes, via de regra, estavam muito mais interessados na "ação" do que nos ideais originais de democracia participativa.

No caso do SDS, aquilo que parecia uma oportunidade ímpar de amplificação do discurso e conquista de novas audiências - levou à destruição da organização. Nem sempre o processo é tão dramático, mas algumas particularidades parecem invariáveis. A busca pela atenção da mídia favorece as atividades mais vistosas, de preferência concentradas num único lugar e esporádicas, em detrimento de um trabalho mais cotidiano e espacialmente disperso. Favorece também a personalização de movimentos coletivos. São, sobretudo, características da televisão, que exige uma ancoragem visual para os assuntos de que trata. Da mesma maneira, na medida em que o candidato possui uma identidade visual imediata, mas o partido não, é razoável indicar a influência da televisão no declínio da política partidária ${ }^{46}$.

Mas a busca pelo "fato político", pelo acontecimento que sensibiliza a atenção dos meios de comunicação e que, através deles, pode atingir a opinião pública, apresenta efeitos diferenciados de acordo com a posição dos agentes no campo político. Aqueles que estão situados na periferia, como era o caso do SDS, são mais fortemente constrangidos a introjetar os critérios midiáticos de apreciação da realidade e procurar a ação espetacular, como forma de romper a cortina da indiferença e, assim, incluir um novo item na agenda pública. Já os que ocupam as posições centrais do campo político podem esperar uma atenção mais ou menos constante dos meios de comunicação para seus atos e palavras, o que significa a possibilidade de alcançar destaque com um dispêndio de esforço bastante menor.

\footnotetext{
45 Gitlin, op. cit. Para outros exemplos, retirados da política européia, e uma interessante análise do fenômeno, ver Champagne, Faire l'opinion, passim.

46 Wattenberg, The decline of American political parties, pp. 90-112.
} 
Os agentes que detêm maior capital político são capazes de orientar o noticiário (e, por conseqüência, a agenda pública) através de entrevistas e declarações. Na cena política brasileira recente, ninguém personificou melhor tal posição do que o senador baiano Antônio Carlos Magalhães. Com um jogo estudado de ameaças, denúncias e insinuações, ele modelava a cobertura política da imprensa e, através dela, forçava o posicionamento de outros agentes do campo político. É claro que o senador incorporou critérios jornalísticos de relevância, utilizando-os para produzir afirmações que despertem interesse suficiente, por seu caráter "bombástico" ou inusitado. Mas usava-os para alcançar seus fins (políticos) próprios. Os imperativos do campo da mídia são, nesse caso, colocados a serviço de uma lógica política autônoma.

\section{A FIXAÇÃO DO CAMPO POLÍTICO}

A influência marcante dos meios de comunicação de massa sobre a produção do capital político e sobre a definição de agenda não deve obscurecer a força das instituições políticas estabelecidas na fixação de um campo político legítimo. Salvo em situações excepcionais, a mídia não questiona os limites dados do que é "a política". As páginas dedicadas ao tema nos jornais estão firmemente ancoradas nas instituições. Tratam do parlamento, das chefias dos poderes executivos, de eleições e de partidos.

A delimitação da política enquanto tal nessas esferas nada possui de natural ou inevitável. Pelo contrário, é fruto da própria luta política e traduz determinada hegemonia. A separação entre política e economia sob o capitalismo, por exemplo, retira do escrutínio público as decisões sobre o investimento produtivo - que, no entanto, têm um impacto mais significativo na vida cotidiana do que a maior parte das medidas governamentais. Também permite que a propriedade privada se coloque como uma barreira às reivindicações de democracia e participação, que assim ficam excluídas de dentro das empresas. Em suma, trata-se de uma demarcação que contribui para a manutenção da ordem capitalista ${ }^{47}$. Por outro lado, há tempos a teoria feminista vem mostrando as implicações - políticas - do insulamento da esfera doméstica em relação à própria política ${ }^{48}$.

\footnotetext{
47 Ver Wood, Democracy against capitalism, pp. 19-48.

48 Entre muitos outros, consultar Pateman, O contrato sexual; Elshtain, "The displacement of politics"; e Miguel, "Teoria política feminista e liberalismo".
} 
Como efeito desta delimitação do campo político, questões importantes (como o direito ao aborto, por exemplo, a proteção ao meioambiente ou a busca por maior autonomia no local de trabalho) recebem o status de periféricas mesmo quando merecem atenção pública. São importantes, talvez, mas não são "verdadeiramente políticas". Os movimentos populares permanecem nas margens da vida política e espera-se que aceitem sua posição subalterna; quando extrapolam suas preocupações específicas, admitidas como legítimas, sempre surgem vozes para denunciar sua "politização" espúria. É o que acontece cada vez que os sindicatos ultrapassam os limites da reivindicação salarial.

Se a luta política é uma luta de "classificações", em que os agentes buscam impor os princípios de "visão e divisão" do mundo social, como diz Bourdieu ${ }^{49}$, então a primeira divisão é aquela que separa um espaço para a própria política. Contribuindo para manter os "profanos" à parte, esta divisão cumpre um papel estabilizador, isto é, conservador; e propicia sobretudo a proteção daqueles que detêm o capital político contra a concorrência de outros agentes, externos. Mas que interessa no momento é observar que os meios de comunicação não desafiam o recorte dominante do que é política; pelo contrário, tendem a uma adaptação imediata a ele, como num reconhecimento tácito de que a tarefa de definir o campo político pertence a seus próprios integrantes.

A simples folheada num jornal diário confirma esta constatação. Nas páginas de política, despontam parlamentares, governantes e chefes partidários. Os movimentos sociais, demandas de minorias ou de mulheres, lutas ambientalistas etc. são, via de regra, relegados ao espaço menos nobre das editorias de "cidades" ou "geral". A principal exceção é o movimento sindical que, junto com os patrões, fica na seção de economia. Política e economia, cabe lembrar, formam universos distintos, que recebem tratamento dessemelhante da mídia. Como observou Michael Schudson, há uma diferença estrutural entre o noticiário político e o noticiário econômico. Enquanto o primeiro se dirige ao leitor enquanto cidadão, o segundo se dirige a ele enquanto investidor ${ }^{50}$.

Pode-se dizer que o noticiário jornalístico, com sua ênfase na disputa por cargos e nas estratégias de partidos e líderes, contribui fortemente para fixar um campo político centrado sobre si mesmo, que se re-

49 Bourdieu, La distinction, p. 559; Bourdieu, Propos sur le champ politique, p. 63.

50 Schudson, The power of news, p. 14. Embora a observação se refira à realidade estadunidense, está se tornando cada vez mais válida também para o Brasil. 
ferencia apenas pela conquista do poder. Os problemas concretos tendem a perder substância, sendo transformados em pivôs para disputas por espaço político. Em qualquer controvérsia pública, a cobertura típica de imprensa tende a destacar as manobras de bastidores, as negociações entre grupos partidários, a formação de alianças e o impacto presumível nas eleições seguintes.

Em suma, a mídia é deferente em relação às principais instituições políticas, conforme se observa pelo destaque que é dado aos ocupantes de seus postos mais importantes. Pode criticá-las, mas raramente se atreve a questionar sua relevância. Isto dá aos grandes líderes políticos uma influência gigantesca sobre o noticiário, que orientam através de declarações públicas, conversas privadas com jornalistas ou com a criação de "factóides" (conforme indicado na seção anterior). Apesar de simplista, a fórmula de Timothy Cook ajuda a compreender esta realidade: entre a imprensa e os governantes, permanece uma divisão de trabalho. Os jornalistas definem o que é interessante, mas são as autoridades que indicam o que é importante ${ }^{51}$.

No jornalismo estadunidense, afirma-se que, em qualquer evento onde esteja presente o presidente da República, ele sempre é o foco da notícia. O que há, em quase todos os lugares, é o foco permanente nos detentores de autoridade política formal. Isto se deve tanto ao fato de que os jornalistas não questionam a definição de política hegemônica quanto à existência de estruturas montadas pelos diversos agentes do campo político, sobretudo governos, para prover a imprensa de notícias ${ }^{52}$. Ao facilitar o trabalho do repórter, em realidade torna-o dependente. No entanto, trata-se de um elemento secundário. No essencial, o que se observa é que, por mais alto seja o grau em que sua influência se faça perceber, a mídia se submete, como que naturalmente, às definições básicas do campo político.

\section{O JORNALISTA E SUAS FONTES}

É importante lembrar ainda que "mídia" e "política" são, a rigor, abstrações. A relação entre elas toma a forma concreta de relações interpessoais entre agentes dos dois campos. Desejo orientar o foco, agora, para

51 Cook, Governing with the news, p. 5.

$52 \mathrm{~A}$ assessoria de imprensa governamental é uma instituição quase coetânea ao próprio jornal; já existia em meados do século 18. Cf. Habermas, Mudança estrutural da esfera pública, p. 36. 
os contatos entre jornalistas, de um lado, e líderes políticos, de outro. De maneira esquemática, é possível distribui-los em três categorias. Em primeiro lugar, os jornalistas "testemunham" eventos políticos que, ainda que possam ser pensados para divulgação na mídia, em princípio ocorreriam mesmo na ausência dela: debates e votações parlamentares, assinaturas de decretos e nomeações, atos de posse, reuniões partidárias. Depois, existem interações relativamente formalizadas entre repórteres e políticos, na forma de entrevistas (coletivas e individuais). Por fim, há a relação cotidiana e informal entre os profissionais de imprensa e aqueles que, no jargão do meio, são chamados de suas "fontes".

Qualquer indivíduo que proporcione dados para a elaboração de uma reportagem é uma fonte. Quem interessa aqui, porém, é aquela fonte mais ou menos permanente, que fornece informações continuadas, e, em algum grau, exclusivas ao mesmo repórter, muitas vezes com a garantia do anonimato na publicação da notícia. No jornalismo em geral, mas no jornalismo político em particular, possuir um bom "portfólio de fontes" é um patrimônio dos mais cobiçados. A informação privativa que elas transmitem propicia uma diferenciação dos concorrentes no campo, a divulgação de eventuais notícias em primeira mão ("furos") e o reconhecimento pelos pares; consolida reputações e favorece o progresso na carreira, permitindo ambicionar posições de maior destaque, como a de colunista. O repórter com boas fontes é aquele que seus pares vêem como bem informado. Em suma, trata-se de um elemento significativo na produção do capital simbólico específico do campo jornalístico.

As boas fontes permitem que o jornalista antecipe os movimentos de governos, partidos ou chefes políticos; tanto podem ser os próprios líderes quanto pessoas de escalão inferior, mas com acesso às principais esferas decisórias. Para que a relação se perpetue, porém, é necessário que ambas as partes a percebam como vantajosa. Como visto, o profissional de imprensa recebe seu ganho na forma de prestígio profissional. Para o político, a condição de fonte permite obter algum grau de influência na condução do noticiário, sobretudo porque existe um forte incentivo para que suas informações exclusivas mereçam um destaque desproporcional à importância intrínseca que teriam, segundo os padrões da imprensa. Essa é a forma que o jornalista tem de valorizar aquilo que diferencia seu material dos concorrentes. Em certos casos, a informação toma a forma de um balão de ensaio, permitindo avaliar o impacto de determinada decisão antes que ela seja de fato tomada. Além disso, existe 
a cobrança tácita dos benefícios que a fonte provê ao repórter, na forma da publicação de notícias de escasso interesse, pelos critérios jornalísticos, mas que são proveitosas ao político.

O exame da micro-relação entre o jornalista e sua fonte permite observar o entrelaçamento de práticas distintas, de agentes que pertencem a diferentes campos e, portanto, se orientam na direção de objetivos diversos. Contudo, devido à dinâmica própria de sua interação, precisam incorporar em alguma medida a lógica um do outro. Sob pena de perder a fonte, o jornalista deve ponderar aquilo que publica, calculando seus efeitos no campo político; e fazer concessões aos interesses do outro, divulgando informações que julga pouco relevantes ou ainda minimizando o destaque de certas notícias (mas nunca ao ponto de comprometer a própria credibilidade). Já a fonte, para manter seu acesso privilegiado à imprensa, deve reconhecer o material que é útil ao jornalista e, sobretudo, manter a própria confiabilidade diante dele, não transmitindo informações equivocadas em busca de benefícios de curto prazo.

Ou seja, não se pode reduzir essa relação ao predomínio da lógica política sobre a jornalística ou vice-versa. Trata-se de uma interação muito mais complexa. Os dois agentes permanecem vinculados a seus próprios campos e buscam a ampliação de seus capitais simbólicos específicos. No entanto, suas ações repercutem mutuamente, o que os obriga a, de alguma maneira, incorporar a lógica do outro em seu cálculo. São necessários ajustes delicados para garantir o máximo de proveito na relação, embora nunca ao ponto de alienar o parceiro.

\section{MODOS DO DISCURSO}

O caráter sempre mais mediatizado da comunicação política leva à adaptação do discurso político às regras da mídia, ao ponto de algumas interpretações indicarem que os "políticos de todas as matizes têm revelado uma tendência a descaracterizar seu próprio discurso e incorporar o estilo midiático", levando à pasteurização dos conteúdos ${ }^{53}$. O problema com este tipo de formulação é que ele supõe a existência de um modo do discurso propriamente político - quando, na verdade, o discurso político muda, de acordo com o contexto histórico em que se inclui e com as possibilidades técnicas de difusão de que dispõe. E a pasteurização denuncia-

53 Sarti, "A construção midiática da política e a crise da representação", p. 3 (ênfase suprimida na citação). 
da talvez se deva mais ao estreitamento do leque de opções políticas, a partir do eclipse dos projetos socialistas, do que aos efeitos da mídia.

Nada disso deve levar a ignorar as transformações que os meios eletrônicos de comunicação impuseram ao discurso político. Na época de predomínio da televisão, em especial, avulta o peso da imagem dos políticos e, o que talvez tenha conseqüências ainda mais importantes, o discurso se torna cada vez mais fragmentário, bloqueando qualquer aprofundamento dos conteúdos ${ }^{54}$. Quanto ao primeiro ponto, cabe observar que a aparência visual não é desprovida de sentido. Um código sofisticado, embora tácito, permite ao público interpretar aquilo que os políticos desejam transmitir pela imagem, do corte de cabelo ao tom do paletó, que podem sinalizar para a "modernidade", para a "austeridade", para a "moderação" e assim por diante.

Já a fragmentação do discurso não é uma imposição técnica da televisão - nada impede que seja transmitida uma fala ininterrupta de duas ou três horas - mas fruto dos usos que se fizeram dela. O resultado é que a fala padrão de um entrevistado num telejornal, por exemplo, é de poucos segundos e as expectativas dos telespectadores se adaptaram a essa regra. Os políticos, por consequiência, também. Abreviar a fala, reduzi-la a umas poucas palavras, de preferência "de efeito", tornou-se imperativo para qualquer candidato à notoriedade midiática.

No entanto, esta adesão também não é desprovida de ambigüidades. Uma das condições de eficácia do discurso político é o estabelecimento de marcas de distinção em relação àqueles comumente veiculados pela mídia. O líder político usa, via de regra, um vocabulário mais elaborado, signo de uma competência específica que o credencia para as posições que ocupa ou almeja ocupar. São termos extraídos do jargão do direito, da economia ou da sociologia, que, mais do que introduzir uma maior sofisticação ao que se diz, servem de elemento diferenciador. É possível fazer uma aproximação entre esta característica do discurso político e o conceito de Kitsch na cultura de massa, tal como o define Umberto Eco: a obra subcultural de consumo que se apresenta ostensivamente como arte, para que, enquanto goza de seus efeitos fáceis, o leitor ou espectador julgue estar desfrutando de uma experiência estética privilegiada ${ }^{55}$. O kitsch político contribui para marcar a distância entre o discurso "fácil" da mídia e o discurso "elaborado" da política, produzindo um efeito legitimador.

54 Miguel, Mito e discurso político, pp. 72-8.

55 Eco, Apocalittici e integrati, pp. 66-72. 
Mais do que isto, trata-se de um mecanismo de dominação que contribui para fechar o campo político à intrusão dos leigos. Como observa Bourdieu, "a linguagem dominante [no campo político] destrói, ao desacreditá-lo, o discurso político espontâneo dos dominados: não lhes deixa outra opção que não o silêncio ou a linguagem emprestada, cuja lógica não é mais a do uso popular, sem ser a do uso culto, linguagem enguiçada, onde as 'palavras elevadas' estão presentes apenas para assinalar a dignidade da intenção expressiva e que, nada podendo transmitir de verdadeiro, de real, de 'sentido', priva aquele que a fala da experiência mesma que julga exprimir" 56 .

Assim, o discurso político trata de não se confundir com o discurso corrente da mídia, preservando suas marcas de distinção. Da mesma forma, a competição política contemporânea exige a utilização das técnicas publicitárias, mas, quando expostas em excesso, elas se tornam contraproducentes ${ }^{57}$. O político fica vulnerável à acusação de não ter personalidade, de não ter pulso, enfim, de não possuir as qualidades especificamente políticas que deveriam credenciá-lo. Ele é alguém que participa do mundo da mídia, mas deve manter a dignidade e não se curvar a todas as suas imposições. Que o então vice-presidente dos Estados Unidos, Al Gore, tenha sido convidado a empinar uma vassoura sobre o nariz num programa de variedades é fato que impressiona, pela degradação de funções públicas que supõe ${ }^{58}$. Só é bom lembrar que Gore se recusou a fazê-lo.

O discurso político precisa se adaptar ao novo ambiente gerado pelos meios de comunicação de massa, bem como a prática política incorpora os recursos que lhe são fornecidos pelas técnicas publicitárias e pelo marketing. Mas é uma apropriação seletiva, que pressupõe uma negociação tácita entre a mídia, que detém os instrumentos de produção da visibilidade social, e o político, que conhece ou intui os limites para além dos quais sua exposição pública se torna contraproducente.

56 Bourdieu, La distinction, p. 538.

57 É possível fazer um paralelo com a retórica, na Grécia antiga, segundo o relato de Ober. A retórica era a ferramenta fundamental para o exercício da liderança política, mas um domínio demasiado evidente de suas técnicas provocava suspeição entre os cidadãos (Ober, Mass and elite in democratic Athens, pp. 166-77).

58 Gabler, Vida: o filme, p. 114. 


\section{CONCLUSÃO}

A compreensão da relação entre o campo da mídia e o campo político é fundamental para o entendimento do funcionamento da política contemporânea. Os meios de comunicação não são canais neutros que "registram" uma realidade que lhes é externa. Também não são penetras que perturbam uma atividade política que, no fundamental, ocorre sem eles; nem são mais, como disse Bernardo Kucinski se referindo aos barões da imprensa da primeira metade do século 20, meros "chantagistas que se imiscuíam no jogo regular de poder das elites dominantes"59. São agentes políticos plenos e, com a força de sua influência, reorganizaram todo o jogo político.

Do reconhecimento do influxo da mídia sobre o campo político não se depreende a dominação da política pelos meios de comunicação. Os efeitos da mídia são variados, de acordo com as situações específicas em que se inserem, e sofrem a ação de contratendências e resistências. Há um processo permanentemente tensionado de embate entre as lógicas do campo midiático e do campo político, que necessita ser observado em detalhe e dentro de sua complexidade. Decretar que a política "se curvou" à mídia é tão estéril quando negar a influência desta sobre a primeira.

O principal erro é julgar que os efeitos da mídia sobre os agentes políticos são uniformes. Em realidade, a influência dos meios de comunicação é diferenciada de acordo com a posição dos agentes no campo político; o volume de capital simbólico que cada um deles possui impõe reações diversas à midiatização da política. De maneira mais ampla, entre os fatores que devem ser levados em consideração estão a configuração das instituições políticas (a começar pelo sistema eleitoral e partidário), a trajetória de cada agente - qual seu ponto de partida, até alcançar a situação atual - e as posições que pretende alcançar. Como hipótese geral, é possível dizer que, quanto menor o volume de capital político (ou quanto mais marginal for a posição no campo político, o que significa a mesma coisa), maior a dependência em relação à mídia. Quanto maior for a marca midiática no capital político (isto é, uma carreira alicerçada na popularidade obtida no ramo do entretenimento ou do jornalismo televisivo), menores as chances de êxito em disputas por cargos-chave. E quanto mais elevadas as posições de poder que se pretende alcançar, maior a necessidade de visibilidade nos meios de comunicação.

${ }^{59}$ Kucinski, A síndrome da antena parabólica, p. 167. 
A relação se torna mais complexa na medida em que o próprio campo da mídia não é autônomo, pois incorpora, em parte (significativa, aliás), objetivos derivados do campo econômico. O círculo se fecha com a percepção da influência mútua entre os campos político e econômico cujas expressões mais evidentes são o financiamento de campanhas eleitorais e o lobby empresarial, para a ação no sentido da economia para a política, e o efeito das medidas de política macroeconômica e dos contratos governamentais, no sentido inverso. A compreensão dessa rede de influências cruzadas permite entender a utilização da mídia como forma de pressão política em busca de objetivos econômicos, um fenômeno comum em estados periféricos, onde jornais ou emissoras de rádio e TV podem estar a serviço de empreiteiras ou concessionárias de serviços públicos, mas observável também em centros maiores ou em âmbito nacional. Neste caso, a colonização da empresa de mídia pela lógica econômica não ocorre na forma da luta pelo mercado, mas da busca deliberada de determinados resultados políticos.

A tarefa de desvendar o jogo político atual passa pelo entendimento da inter-relação entre esses três campos. É um esforço que não admite atalhos simplificadores, do tipo $A$ determina $B$; antes, exige o reconhecimento das tensões latentes (e por vezes até expressas) que marcam a complexa conjugação entre as influências mútuas, resistências, composições, ajustes delicados e anseios por autonomia que animam os diversos agentes de cada campo.

\section{REFERÊNCIAS BIBLIOGRÁFICAS}

BAGDIKIAN, Ben H. - The media monopoly. Edição atualizada. Boston: Beacon Press, 1997.

BALANDIER, Georges - Le pouvoir sur scènes. Edição ampliada. Paris: Balland, 1992.

BERGER, Christa - Campos em confronto: a terra e o texto. Porto Alegre: Editora da Universidade, 1998.

BOORSTIN, Daniel J. - The image: a guide to pseudo-events in America. Reed. New York: Vintage, 1992.

BOURDIEU, Pierre — La distinction: critique sociale du jugement. Paris: Minuit, 1979.

"L'opinion publique n'existe pas", em Questions de sociologie. Paris: Minuit, 1984.

“A representação política. Elementos para uma teoria do campo político", em $O$ poder simbólico. Lisboa: Difel, 1990.

Sur la télévision, suivi de L'emprise du journalisme. Paris: Liber, 1996.

- Méditations pascaliennes. Paris: Seuil, 1997.

Propos sur le champ politique. Lyon: Presses Universitaires de Lyon, 2000.

(com Loïc J. D. WACQUANT) — Réponses. Paris: Seuil, 1992. 
CAPPELLA, Joseph N. e Kathleen Hall JAMIESON - Spiral of cynicism: the press and the public good. Oxford: Oxford University Press, 1997.

CASTELLS, Manuel - O poder da identidade. S. Paulo: Paz e Terra, 1999.

CECI, Stephen J. e Edward L. KAIN - "Jumping on the bandwagon with the underdog: the impact of attitude polls on polling behavior". Public Opinion Quaterly, vol. 46, $\mathrm{n}^{\circ}$ 2. New York, 1982, pp. 228-42.

CHAMPAGNE, Patrick - Faire l'opinion: le nouveau jeu politique. Paris: Minuit, 1990.

COHEN, Bernard C. - The press and foreign policy. Princeton: Princeton University Press, 1969.

COOK, Timothy E. - Governing with the news: the news media as a political institution. Chicago: The University of Chicago Press, 1998.

DAHL, Robert A. - Democracy and its critics. New Haven: Yale University Press, 1989.

Um prefácio à democracia econômica. Rio de Janeiro: Jorge Zahar, 1989.

DIAMOND, Edwin e Stephen BATES - The spot: the rise of political advertising on television. Edição atualizada. Cambridge (Mass.): The MIT Press, 1988.

DIZARD Jr., Wilson - A nova mídia: a comunicação de massa na era da informação. Rio de Janeiro: Jorge Zahar, 1998.

ECO, Umberto - Apocalittici e integrati: comunicazioni di massa e teorie della cultura di massa. Reed. Milano: Bompiani, 1993.

EDELMAN, Murray — The symbolic uses of politics. Edição ampliada. Urbana: University of Illinois Press, 1985.

ELSHTAIN, Jean Bethke - "The displacement of politics", em Jeff Weintraub e Krishan Kumar (eds.) - Public and private in thought and practice: perspectives on a grand dichotomy. Chicago: The University of Chicago Press, 1997.

ENTMAN, Robert M. - Democracy without citizens: media and the decay of American politics. Oxford: Oxford University Press, 1989.

"Framing: toward clarification of a fractured paradigm". Journal of Communication, vol. 43, $\mathrm{n}^{\circ}$ 4. Austin, 1993, pp. 51-8.

FALLOWS, James - Detonando a notícia: como a mídia corrói a democracia americana. Rio de Janeiro: Civilização Brasileira, 1997.

FRASER, Nancy - "Rethinking the public sphere: a contribution to the critique of actually existing democracy", em Craig Calhoun (ed.) - Habermas and the public sphere. Cambridge (MA): The MIT Press, 1992.

FRIAS Filho, Otávio - "Vendem-se candidatos". Folha de S. Paulo, 4/8/1994, p. 2.

FRISTCH, Philippe - "Introduction" a Pierre Bourdieu — Propos sur le champ politique. Lyon: Presses Universitaires de Lyon, 2000.

FUKS, Mario - "Definição de agenda, debate público e problemas sociais". BIB - Revista Brasileira de Informação Bibliográfica em Ciências Sociais, $\mathrm{n}^{\circ}$ 49. Rio de Janeiro, 2000, pp. 79-94.

GABLER, Neal - Vida, o filme: como o entretenimento conquistou a realidade. S. Paulo: Companhia das Letras, 1999.

GAMSON, William A. — Talking politics. Cambridge: Cambridge University Press, 1992.

GARNHAM, Nicholas - "The media and the public sphere", em Craig Calhoun (ed.) Habermas and the public sphere. Cambridge (MA): The MIT Press, 1992.

GITLIN, Todd - The whole world is watching: mass media in the making \& unmaking of the new left. Berkeley: University of California Press, 1980.

GOFFMAN, Erving - Frame analysis: an essay on the organization of experience. Boston: Northeastern University Press, 1974.

GOMES, Wilson - "Propaganda política, ética e democracia", em Heloiza Matos (org.) Mídia, eleições e democracia. S. Paulo: Scritta, 1994.

GRABER, Doris - Processing the news: how the people tame the information tide. Edição revista. New York: Longman, 1988. 
HABERMAS, Jürgen - Mudança estrutural da esfera pública. Rio de Janeiro: Tempo Brasileiro, 1984.

HALLIN, Daniel C. - The "uncensored" war: the media and Vietnam. Berkeley: University of California Press, 1986

HUNTINGTON, Samuel P. - "The United States", em Michel J. Crozier, Samuel P. Huntington e Joji Watanuki - The crisis of democracy: report on the governability of democracies to the Trilateral Comission. New York: New York University Press, 1975.

IYENGAR, Shanto - Is anyone responsible? How television frames political issues. Chicago: The University of Chicago Press, 1991.

JANEWAY, Michael - Republic of denial: press, politics, and public life. New Haven: Yale University Press, 1999.

JENKINS, Richard - Pierre Bourdieu. London: Routledge, 1992.

KUCINSKI, Bernardo - A síndrome da antena parabólica: ética no jornalismo brasileiro. S. Paulo: Fundação Perseu Abramo, 1998.

LASCH, Christopher - A rebelião das elites e a traição da democracia. Rio de Janeiro: Ediouro, 1995.

LIPPMANN, Walter - Public opinion. Reed. New York: Free Press, 1997.

LÖWY, Michael - "A escola de Frankfurt e a modernidade: Benjamin e Habermas". Novos Estudos Cebrap, $\mathrm{n}^{\circ}$ 32. S. Paulo, 1992, pp. 119-27.

MANSBRIDGE, Jane M. - Beyond adversary democracy. Edição revista. Chicago: The University of Chicago Press, 1983.

MCCHESNEY, Robert W. - Rich media, poor democracy: communication politics in dubious times. Urbana: University of Illinois Press, 1999.

MCCOMBS, Maxwell e Donald SHAw - "The agenda-setting function of mass media". Public Opinion Quaterly, vol. 36, $\mathrm{n}^{\circ}$ 2. New York, 1972, pp. 176-87.

MEYROWITZ, Joshua - No sense of place: the impact of electronic media on social behavior. Oxford: Oxford University Press, 1985.

MIGUEL, Luis Felipe - "Mídia e eleições: a campanha de 1998 na Rede Globo". Dados, vol. 42, n 2. Rio de Janeiro, 1999, pp. 253-76.

Mito e discurso político: uma análise a partir da campanha eleitoral de 1994. Campinas: Editora da Unicamp, 2000.

"Democracia e novas tecnologias da informação". Revista Internacional de Estudos Políticos, vol. 2, n 2. Rio de Janeiro, 2000, pp. 163-84.

"Teoria política feminista e liberalismo: o caso das cotas de representação". Revista Brasileira de Ciências Sociais, $\mathrm{n}^{\circ}$ 44. S. Paulo, 2000, pp. 91-102.

MOISÉS, José Álvaro - Os brasileiros e a democracia: bases sócio-políticas da legitimidade democrática. S. Paulo: Ática, 1995.

NEUMAN, W. Russell, Marion R. Just e Ann N. CRIGLER - Common knowledge: news and the construction of political meaning. Chicago: The University of Chicago Press, 1992.

NOELLE-NEUMAN, Elisabeth — La espiral del silencio: opinión pública, nuestra piel social. Barcelona: Paidós, 1995.

OBER, Josiah - Mass and elite in democratic Athens: rethoric, ideology, and the power of the people. Princeton: Princeton University Press, 1989.

PAGE, Benjamin I. - Who deliberates? Mass media in modern democracy. Chicago: The University of Chicago Press, 1996.

PATEMAN, Carole - O contrato sexual. S. Paulo: Paz e Terra, 1993.

PINTO, Louis - Pierre Bourdieu et la théorie du monde social. Paris: Albin Michel, 1998.

PUTNAM, Robert D. - "Tuning in, tuning out: the strange disappearance of social capital in America”. PS: Political Science \& Politics, vol. XXVIII(4). Washington, 1995, pp. 664-83. 
ROSENBERG, Shawn W. e Patrick MCCAFFERTY — "The image and the vote: manipulating voters' preferences". Public Opinion Quaterly, vol. 51, n ${ }^{\circ}$. Chicago, 1987, pp. 31-47.

RUBIM, Antônio Albino Canelas — Comunicação e política. S. Paulo: Hacker, 2000.

SARTI, Ingrid - “A construção midiática da política e a crise da representação". Paper apresentado no XXIV Encontro Anual da Anpocs. Petrópolis, 2000.

SARTORI, Giovanni - "Videpolitica". Rivista Italiana di Scienza Politica, vol. XIX, nº 2. Roma, 1989, pp. 185-98.

A teoria da democracia revisitada, vol. 1. S. Paulo: Ática, 1994.

Homo videns: la sociedad teledirigida. Buenos Aires: Taurus, 1998.

SCHUDSON, Michael - The power of news. Cambridge (Mass.): Harvard University Press, 1995.

URBINATI, Nadia - "Representation as advocay: a study of democratic deliberation". Political Theory, vol. 28(6). Thousand Oaks, 2000, pp. 758-86.

WATTENBERG, Martin P. - The decline of American political parties, 1952-1996. Cambridge (Mass.): Harvard University Press, 1998.

WOOD, Ellen Meiksins - Democracy against capitalism: renewing historical materialism. Cambridge: Cambridge University Press, 1995. 